\title{
Normativity all the way down: from normative realism to pannormism
}

\author{
Einar Duenger Bohn'
}

Received: 17 August 2016/ Accepted: 19 April 2017

(C) The Author(s) 2017. This article is an open access publication

\begin{abstract}
In this paper, I will give an argument for what I call pannormism, the view according to which if $\mathrm{x}$ instantiates a metaphysically basic normative property $\mathrm{F}$, then whatever grounds the being of $x$ also instantiates F. In slogan form: if there is normativity, there is normativity all the way down. Such pannormism is in many ways analogous to panpsychism, and my discussion also contains an important lesson for panpsychism, a way to avoid its so-called combination problem. In Sect. 1, I present the argument; in Sect. 2, I discuss its conclusion.
\end{abstract}

Keywords Pannormism $\cdot$ Normative realism $\cdot$ Grounding $\cdot$ Panpsychism

\section{Pannormism}

The argument has three background premises.

The first premise is that there is at least one normative property $\mathrm{F}$ that is metaphysically basic in the sense that neither it nor its instantiations have a full metaphysical explanation (of any kind) in terms other than F. ${ }^{1}$ For the sake of simplicity, let's assume good and bad are such properties. Then, something is just bad, and there is no full metaphysical explanation of that not involving the property bad. This is of course a

\footnotetext{
1 Note that I here take that to mean it is also normatively basic. I henceforth use 'metaphysically basic' or just 'basic' for sub-factual objects and properties (and relations) whose being has no full metaphysical explanation in other terms (e.g. real definition (cf. Rosen 2015a, b), or metaphysical reduction); and I use 'metaphysically fundamental' or just 'fundamental' for facts whose obtaining has no full metaphysical explanation, which in the case of facts mean no full ground (see below). Note also that I am not claiming that all normative properties are metaphysically basic, only that at least one is.
}

$凶$ Einar Duenger Bohn

einar.d.bohn@uia.no; einarduengerbohn@gmail.com

1 University of Agder, Kristiansand, Norway 
controversial position, but many good philosophers have argued it's true, including some very recent ones (e.g. Shafer-Landau 2003; Enoch 2007; Fitzpatrick 2008; Parfit $2011)^{2}$. Such normative realism is simply a background premise in what follows. The main reason for it is as with most cases of (irreducible) realism about X: we seem to fail to be able to fully explain $\mathrm{X}$ in other kinds of terms. For what it's worth, I for one find it incredible that there are no normative properties, but find it impossible to explain how there can be unless they are ultimately explained in terms of some metaphysically basic normative properties. Just like the Humean says that no descriptive properties or facts entail a normative property or fact, I say no descriptive properties or facts fully metaphysically explain a normative property or fact (cf. second background premise below).

It's worth noting that if you deny such normative realism, the following argument should still be of interest to you, either as a conditional argument or perhaps as a strengthened reductio against this first background premise. ${ }^{3}$

The second background premise is that the obtaining (or being) of some facts is grounded in the obtaining (or being) of other facts. ${ }^{4}$ For example, the fact that an epileptic seizure obtains is grounded in the facts of some overactive, uncontrolled neuron firings in the brain obtaining (collectively). Now, there are various ways of understanding and formalizing such talk, many of which is compatible with all I will go on to say below, but for the sake of clarity and definiteness, I will here employ a particular notion of grounding in the spirit of Fine $(2001,2002)$ and Rosen $(2010) .^{5}$ This notion is perhaps the closest we get to a standard notion of grounding these days (cf. Bliss and Trogdon 2014; Raven 2015), so I'll henceforth call it the standard notion of grounding (SNG). By SNG, grounding is a many-one relation between a plurality of one or more facts collectively and a single fact. ${ }^{6}$ SNG imposes what we might (with some formal slack) call a strict partial order on its domain: ${ }^{7}$ no fact even partially grounds itself (irreflexivity); if a fact $\mathrm{p}$ is grounded in some facts qq, then no one of qq is even partially grounded in $\mathrm{p}$ (asymmetric); and if a fact $\mathrm{p}$ is grounded in some facts q,rr, and q is grounded in some facts ss, then p is grounded in rr,ss

\footnotetext{
2 Some of these try to give a metaphysical explanation of the normative property $\mathrm{F}$, but not fully in terms not involving $\mathrm{F}$.

3 Note that I henceforth exclusively talk of evaluative normative properties rather than deontic normative properties, but nothing hinges on this. I believe the same kind of arguments hold of deontic properties.

4 I henceforth use 'obtaining', 'being', 'the being of' and 'the nature of' interchangeably, but I try to keep 'existence' out of it. I also use 'ground' exclusively for a relation among facts. Nothing important hinges on this terminology.

5 For a similar, but more general notion including both facts and sub-factual entities, see Schaffer (2009).

6 More formally (though I am reluctant to do so more metaphysically), we might think of a fact as a true proposition. I thus also allow general facts, e.g. of the form "All Fs are G". I should also warn the reader that I henceforth employ (both first-order and propositional) plural logic without shame, but will explain the basics along the way. For more details on first-order plural logic, see Boolos (1986), Yi (2005, 2006) or Oliver and Smiley (2013).

7 Following Rosen (2010), I here assume the so-called predicate approach rather than the so-called operator approach, and I assume that grounding is factive. Note that for the argument to come I don't need all the assumptions mentioned here and below, but I use them all here for the sake of having a relatively clear notion in mind throughout. See Bliss and Trogdon (2014) and Raven (2015) for references to further discussion on each of the features I here simply assume.
} 
(transitivity/cut). Also, if a fact $\mathrm{p}$ is grounded in some facts qq, then, necessarily, if qq obtain, then $\mathrm{p}$ obtains (necessitation); if a fact $\mathrm{p}$ is grounded in some facts qq, then it is not the case that for any $\mathrm{r}, \mathrm{p}$ is grounded in qq,r (non-monotonicity); and if a fact $\mathrm{p}$ is grounded in some facts qq, then qq fully and constitutively metaphysically explain $\mathrm{p}$ (explanatoriness). This last feature is important and will be further discussed below. As we'll see, I also thereby assume the extensionality of grounding: no one and the same plurality can ground two distinct facts.

We say that a fact $\mathrm{p}$ is partially grounded in some facts qq iff there are some facts rr such that $\mathrm{p}$ is fully grounded in rr and qq are among rr; $\mathrm{p}$ being fully grounded in $\mathrm{rr}$ being our official primitive $(\mathrm{G})$, but intuitively characterized as providing a complete and constitutive metaphysical explanation of $p .{ }^{8} \mathrm{I}$ do not assume that grounding is (metaphysically) well-founded (cf. Schaffer 2009; Dixon 2016; Rabin and Rabern 2016). In fact, I believe grounding might be non-well-founded, indefinitely descending (see e.g. Bliss 2013; Bohn 2017). ${ }^{9}$

It's worth emphasizing that my argument to come does not rest on any particular notion of grounding like SNG just sketched. In fact, I believe it doesn't even rest on a notion of grounding at all. There are other conceivable ways to understand the dependence relation involved (cf. Wilson 2014), but I cannot and will not explore such options here.

The third background premise is that metaphysically emergent properties are impossible. In our terminology, a metaphysically emergent property is a metaphysically basic property whose instantiator has a ground as per SNG above (cf. Barnes 2012), but the property instantiation has no full explanation in terms of that ground. ${ }^{10}$ For example, contra panpsychism (e.g. Nagel 1979; Strawson 2006; Chalmers 2013), some might think that consciousness is such an emergent property because it is metaphysically basic, instantiated by (a part of) a body whose being has a ground, but it has no full explanation in terms of that ground. ${ }^{11}$

\footnotetext{
8 One should here distinguish between, on the one hand, grounding being an explanation, and on the other hand, grounding backing an explanation. I here assume the former, though I believe nothing hinges on this.

9 Note that I will henceforth occasionally speak of sub-factual things (objects, properties and relations) whose being has a ground, but formally all talk of ground should be couched in terms of facts, not sub-factual things. Sub-factual things might have other kinds of metaphysical explanations, e.g. real definitions.

10 I take it this is also a case of Wilson's (2015) schema for strong emergence. For an overview of emergence, see O'Connor and Wong (2015). Again, our terminology is not essential here. Note also that strictly speaking the argument below doesn't need the fully general claim that no property can be emergent, only the much more restricted claim that normative properties aren't in fact emergent. But the restricted claim seems ad hoc to me (see also the discussion of panpsychism below).

11 Note that by my characterizations of metaphysically basic properties and metaphysically emergent properties there can be metaphysically basic properties instantiated by things whose being has a ground, without those properties being metaphysically emergent properties. For example, assume two objects a and $\mathrm{b}$ whose being has a ground stand in a certain distance to each other, and that distance is a metaphysically basic relation. Distance is still not emergent, because its instantiation between a and b has a full metaphysical explanation in terms of the (pluralities of) objects that ground a and b standing in a certain distance to each other, i.e. it has no full explanation in other terms (so it's basic), but it has a full explanation in terms of the ground of a and b (so it's not emergent). There is a fully general story to be told here, but it's too long to be told here. Thanks to Kelly Trogdon for pressing me on this point.
} 
The question of emergence is too big to fully tackle here, but I will give four sets of considerations that hopefully add some strength to the general case against it already out there in the literature.

First, on the one hand, most of the philosophical literature on strong metaphysical emergence deals more with the question of what such emergence is than with the question of whether there is or can be any such emergence to begin with (cf. O'Connor and Wong 2015; Wilson 2015). On the other hand, most of the scientific literature on emergence deals more with the question of whether there is epistemic emergenceproperties of whole systems that cannot be predicted from the properties of the parts of that system - than with whether there is or can be any strong metaphysical emergence (cf. Bedau and Humphrey 2008). But the above premise needed for the argument below is whether there is or can be any strong metaphysical emergence. So, it is highly unclear to what extent there really is a case against our premise out there at all. Of course, that is not saying the premise is true; for that purpose we need, among other things, the next three sets of considerations.

Second, there simply are no good candidates for an actual case of strong metaphysical emergence. The three candidates most often mentioned are consciousness, quantum entanglement, and life, but none of them need be and therefore should not be interpreted as a case of strong metaphysical emergence. Or at least so I will argue.

Consider the last case first: life. The claim here is that life, as studied in the science of artificial life (see e.g. Boden 1996), is an emergent property of a system of individuals because it turns out to be impossible to adequately describe the behavior of the whole system on the basis of the behavior of each individual in that system. That is, the behavior of the whole system can only be adequately explained in terms of so-called non-linear properties, meaning one must start with properties of the whole system rather than with properties of the individuals in it. But, or so I claim, the system is nothing but the individuals in it, so the non-linear properties are better treated as cases of a plural collective property of the individuals in the system than as an emergent property of the system. In the study of artificial life, the individuals of the system are treated as basic entities and the system as the derivative entity being grounded in them. So, a plural collective property of the individuals in the system is then by definition not an emergent property in our sense of the term. In short, life is a plural collective property, not an emergent property.

Next, consider the second case: quantum entanglement. The claim here is that quantum entanglement is an emergent property of a system of particles (e.g. McDaniel 2007, 2008; Schaffer 2010). Quantum entanglement means that two (or more) particles are perfectly correlated in terms of a quantitative property such that by measuring it of the one (getting, say, spin up) immediately guarantees a certain measure of the other (in this case, spin down), and so independently of the distance between them. This holistic feature is guaranteed by the very formalism of quantum mechanics (see e.g. Susskin and Friedman 2015). But, or so I claim, just as in the case of life above, this is no case of an emergent property in our sense of the term. The system of particles is nothing but the particles, so entanglement is better treated as a case of a plural collective property of the particles in the system than as an emergent property of the system. In quantum mechanics, the particles of the system are basic entities and the system is the derivative entity grounded in them. So, a plural collective property of the 
particles in the system is then by definition not an emergent property in our sense of the term. In short, quantum entanglement is a plural collective property, not an emergent property.

Finally, consider the first case: consciousness. Some, e.g. McDaniel (2007, 2008), claims that consciousness is an emergent property because it is instantiated by (a part of) a body whose being has a ground, but its instantiation has no full metaphysical explanation in other terms. I believe this is the most viable candidate for actual emergence, but given the next two sets of considerations, and in the spirit of the argument below, it is not a convincing case. There are alternative explanations that don't postulate emergence, even if consciousness is an irreducibly real phenomenon. The alternatives are versions of panpsychism, which I will discuss below. As we'll soon see, panpsychism and pannormism are in many ways analogous positions. ${ }^{12}$

Third, some, e.g. McDaniel (2007, 2008), have argued that emergence is conceivable and therefore possible, even if it's not actually the case. But if emergence is possible, then it is not impossible, so our third background premise is false. But this objection is unconvincing. First of all, conceivability does not entail possibility (McDaniel doesn't claim it does). Second, the conceivability involved is so-called negative conceivability, which only (at best) gives us that it might be the case for all we know, which only gives us epistemic possibility, not metaphysical possibility. Third, given all the considerations so far plus the next and final set of considerations, together with the possibility of panpsychism discussed below, the above conceivability argument gives us no convincing case for the metaphysical possibility of strong metaphysical emergence. Fourth, it is worth repeating that the argument for pannormism below can be run on the weaker premise that there actually is no emergence, and thus be compatible with the mere metaphysical possibility of emergence. But, as the next set of considerations and the discussion of the principle TDP below indicates, we have no good reason to ever postulate strong metaphysical emergence.

Fourth, it is a good methodological rule to not postulate emergence beyond necessity. At least it's on a par with both the rule of not postulating necessary connections beyond necessity as well as the rule of not postulating entities beyond necessity. All three rules are intended to rule out unnecessary and unexplained things. So we should not postulate emergence unless we have to; if my arguments are correct, we don't have to; so we shouldn't.

Of course, none of the above reasons against emergence are decisive, but together they add some strength to the general case against it. The most important part for present purposes is that there is no convincing actual case of emergence, and methodological reasons speak against ever postulating it. What's more, when we soon compare pannormism with panpsychism we see that a ban on emergence is also a premise for panpsychism. So it might be considered a premise for a more general research program, a research program centering on what I below call the trickle down principle (TDP). Importantly, this research program considers TDP a solution to the problem

\footnotetext{
12 Note also that Tononi's (e.g. 2008) integrated information theory of consciousness can, as in the cases of artificial life and quantum entanglement above, be interpreted as postulating consciousness as a plural collective property.
} 
of understanding emergence. On the flip side, the fans of emergence might thus find the argument to rather be a reductio in their favor.

Finally, here is the direct argument for what I call pannormism. Premise 1: some a instantiates a metaphysically basic normative property F. ${ }^{13}$ Premise 2: the being of $a$ is grounded (as per SNG) in the being of some plurality (of one or more) bb. Premise 3: If Premises 1-2, then either F is not metaphysically basic, or F is emergent, or F is a property of $b b$. But, by Premise $1, \mathrm{~F}$ is metaphysically basic, and by the third background premise above emergent properties are impossible, so it logically follows that $\mathrm{F}$ is a property of $b b .^{14}$

For a toy example, consider a really bad epileptic seizure. Assume its property of being bad is basic, and that the (being of the) epileptic seizure is grounded in the (being of the) uncontrolled, overactive neuron firings in the brain. Then those uncontrolled, overactive neuron firings in the brain are bad.

Formally, we thus get the following general principle, which I call the trickle-down principle:

$$
(\mathrm{TDP}):([\mathrm{Fx}] \&[\mathrm{Byy}] \mathrm{G}[\mathrm{Bx}]) \rightarrow[\mathrm{Fyy}]
$$

where ' $\mathrm{F}$ ' represents a metaphysically basic normative property, ' $\mathrm{B}$ ' represents being (or the being of, the obtaining of), '[Byy $] \mathrm{G}[\mathrm{Bx}]$ ' means that the being of yy grounds the being of $\mathrm{x}$, and 'Fyy' means that the plurality yy has the property $\mathrm{F}$.

This last claim, corresponding to the conclusion of the argument above, is ambiguous, a precisification of which leads to at least three different positions. But before we consider those three different positions, note, in any case, an interesting consequence of TDP: by SNG, G is a strict partial order, so it follows, by the transitivity of $\mathrm{G}$ in particular, that $\mathrm{F}$ holds not only of yy, but all the way down the grounding chain of the being of x, possibly ad infinitum, without end (cf. Bliss 2013; Bohn 2017). That is, if the grounding chain has a limit, F ends there, but if it has no limit, F holds all the way down, ad infinitum, without end.

This latter possibility of indefinite descent in terms of ground does not mean that the normative property $\mathrm{F}$ is emergent because each one of F's instantiations has a full explanation in terms of the ground of its instantiator; $F$ is thus by definition not emergent (though it is still basic). Going back to our toy example above, if the epileptic seizure is bad, and the being of the epileptic seizure is grounded in the being of some uncontrolled, overactive neuron firings in the brain, then those uncontrolled, overactive neuron firings are bad, and if the being of those uncontrolled, overactive neuron firings are grounded in the being of some atomic behavior, then that atomic behavior is bad, and if the being of that atomic behavior is grounded in the being of some sub-atomic behavior, then that sub-atomic behavior is bad, and if the being of that sub-atomic behavior is grounded in ..., and so on possibly ad infinitum, without end.

\footnotetext{
13 Note that I take that to mean the property is also normatively basic, i.e. not only does it not have any full metaphysical explanation for why it is instantiated, but it also has no full normative explanation for why it is instantaited.

14 Note that F is thus "multigrade" in the sense that it can take both singular and plural subjects.
} 
In such a scenario of indefinite descent, one might of course worry that normativity could never arise, since there is no first level at which it arises. But that is a general worry with indefinite descent as such, not a particular worry with pannormism in particular. The question is: How could anything arise if there is no first level? But this worry is well handled in the literature on grounding (see e.g. Bliss 2013; Bohn 2017), and, in any case, not something we should discuss here. If you are worried about indefinite descent, you should be skeptical about that in general, not pannormism in particular. In any case, the possibility of indefinite descent is orthogonal to pannormism.

Now, as I said above, the conclusion of the argument, Fyy, is ambiguous, with at least three precisifications. First precisification (Weak distributivity): Fyy iff at least one of yy is F. Second precisification (Strong distributivity): Fyy iff each one of yy is F. Third precisification (Collectivity): Fyy iff all of yy together has F, but no one of them individually has $\mathrm{F}^{15}$ These precisifications of the conclusion lead to three different positions.

First position (Weak distributivity): in this case, if $\mathrm{x}$ has $\mathrm{F}$, then at least one of the constituents in X's ground has $\mathrm{F}$ too, and so on down the grounding chain of $\mathrm{x} .{ }^{16} \mathrm{I}$ don't want to rule out any one of the three resulting positions, but this first position seems objectionably arbitrary, to my mind. Going back to our toy example again, it amounts to at least one of the overactive, uncontrolled neuron firings being bad, but if not each one of them or all of them are bad, then the question immediately rises: which ones are bad and which ones are not bad? Any answer seems objectionably arbitrary.

Second position (Strong distributivity): in this case, if $\mathrm{x}$ has $\mathrm{F}$, then each one of the constituents in X's ground has F too, and so on down the grounding chain of $\mathrm{x}$. Again, I don't want to rule out any one of the three resulting positions, but this second position seems simply incredible, to my mind. Going back to our toy example again, it amounts to each one of the overactive, uncontrolled neuron firings being bad, but I have a hard time seeing, for any one of them, why it alone is bad rather than not bad. Presumably, it can be good too. Also, I take it, it alone would not be bad in the exact same way that the epileptic seizure is bad, but then the question immediately arises: what makes one but not another combination of such things bad in the way of the epileptic seizure? This position and problem will be further discussed in Sect. 2 below, in connection with panpsychism.

Third position (Collectivity): in this case, if $\mathrm{x}$ has $\mathrm{F}$, then all of the constituents collectively in x's ground has F too, but no one of them individually, and so on down the grounding chain of $\mathrm{x}$. Of all three positions, this seems the most plausible, to my mind. Going back to our toy example again, it amounts to all of the overactive, uncontrolled neuron firings being bad together, collectively, but not any one of them individually.

\footnotetext{
15 The intuitive difference between distributive and collective predication is this: 'The apples are on the table' is distributive because they are all on the table, but each one of them is on the table too, but 'The students surrounded the faculty building' is collective because they surrounded the building together, but no one of them did it alone.

16 Note that there could also be normativity holding of proper sub-collections of yy, but I will ignore such complications here. Nothing important hinges on this, as far as I can tell. Note also that I sometimes talk as if an object is grounded, but, formally, by SNG, I should say that it is the being (or nature) of the object that is grounded, not the object itself (nor its existence). Nothing hinges on this terminological nicety for present purposes.
} 
This is as it should be, if the epileptic seizure is bad, and the being of the epileptic seizure is completely and constitutively metaphysically explained (grounded) in terms of the collective being of the overactive, uncontrolled neuron firings. In short, if the being of the seizure is nothing more than the collective being of the underlying neuron activity, then if the former is bad, the latter must be bad too (on pain of emergence); but it does not follow that each one of the constituents of the collective behavior is in any way bad. ${ }^{17}$

Since this third position will be our main focus below, it is worth emphasizing exactly how the normative property trickles downwards. If a is bad, and a is grounded in $b b$, then bb are collectively bad. But if each $b_{i}$ in bb is in turn grounded in a plurality $\mathrm{cc}_{\mathrm{i}}$, then there will be a plurality of pluralities $\mathrm{cc}_{1}, \mathrm{cc}_{2}, \ldots, \mathrm{cc}_{\mathrm{n}}$ that are collectively bad. But this plurality is nothing but the plurality of all members of each $\mathrm{cc}_{\mathrm{i}}$, so all those members are what are collectively bad. And so it goes until you reach the basic level of instantiators that have no further ground, if there is such a basic level (if there is no such basic level, it goes on ad infinitum, with no end).

\section{Discussion}

Premises 1 and 2 of the direct argument are much discussed and well defended in the seemingly continuously expanding literature on the matters, and I have nothing new to add in their defense here. For present purposes, premise 3 is the crux: if premises 1 and 2 are true, then either $\mathrm{F}$ is not metaphysically basic, or $\mathrm{F}$ is emergent, or $\mathrm{F}$ is a property of bb. Assume premise 1 and 2 . Then $\mathrm{F}$ is a real property of a, but the being of a is grounded in the being of bb, which means, by our assumption of SNG, that the being of bb provides a complete constitutive metaphysical explanation of the being of a; i.e. there is nothing more to the being of a than the being of bb. But if there is thus nothing more to the being of a than there is to the being of bb, then if $F$ is not a property of bb, it must either not be a metaphysically basic property after all, but rather have a full explanation in terms of some other properties (presumably of bb), or simply be an emergent property of a; i.e. there are no other options. But $\mathrm{F}$ is by assumption a metaphysically basic property, and emergent properties are impossible, so $\mathrm{F}$ is a property of bb. And, I claimed above, the most plausible disambiguation of this conclusion is the third position above (based on collectivity).

Before we discuss some potential objections to this argument, it is worth taking a minor detour into the matter of consciousness. The acute reader will have noticed that the above argument is very similar to Nagel's (1979) argument for panpsychism, the view according to which the basic constituents of the world have conscious properties. This similarity is intentional on my side, because though the two arguments are structurally similar, panpsychism is only similar to one of the three resulting positions based on the argument, namely the second position (based on strong distributivity). But that position was much less plausible than the third position (based on collectivity). This proves an important lesson missed by proponents of panpsychism (cf. e.g. Nagel 1979; Strawson 2006; Chalmers 2013).

17 Relatedly, a band can be bad even though no one musician in the band is bad. 
Consider the following Nagelian argument for panpsychism (cf. Nagel 1979). ${ }^{18}$ Some composite physical objects have metaphysically basic conscious properties; but the being of these composite physical objects are grounded in the being of the same kind of basic physical objects as all other physical composites in nature; and emergent properties are impossible; so the basic physical objects whose being ground the being of all composite physical objects must have conscious properties (on pain of consciousness not being metaphysically basic after all).

Note some important differences from the earlier argument concerning normative properties, i.e. what I called pannormism. In the case of the Nagelian argument, the conclusion is often taken to be that any one of physical reality's basic objects, or at least any one of a kind of physical reality's basic objects has conscious properties (cf. Nagel 1979; Strawson 2006), which almost corresponds to the second position above in the case of normativity (based on strong distributivity). But only almost because the second position in the case of normativity only entails that each one in the ground of $a$ grounded thing is normative, not that each one (perhaps of a kind) in the ground for any grounded thing is normative. In short, the second position of pannormism does not entail pannormism in the strict sense of the term. ${ }^{19}$ But I claimed above that the second position was far less plausible (in fact, close to incredible) compared to the third position (based on collectivity). I claim, for the same reasons, the same in the case of panpsychism. Consider an arbitrary composite physical object $\mathrm{x}$ with metaphysically basic conscious properties. Assume the being of $\mathrm{x}$ is grounded in the being of some more basic physical objects yy, and that emergent properties are impossible. We should still only conclude that all of yy collectively have conscious properties, not that each one of them has conscious properties. The conscious properties would then be (identical with) metaphysically basic plural collective properties. By grounding being a strict partial order, such metaphysically basic plural collective properties would trickle all the way down the grounding chain of $\mathrm{x}$, possibly $a d$ infinitum, without end, just like we saw in the case of normativity above. In short, there would be consciousness all the way down, no matter how far.

There is likewise no reason to conclude that any one (possibly of a kind) of physical reality's (possibly more and more) basic objects has conscious properties, but only that some pluralities of them do, and each such plurality collectively. In other words, there is no reason to conclude that panpsychism is true in the strict sense of the term, but rather that what we might call pluralized panpsychism is true, the more moderate view according to which some pluralities of (possibly more and more) basic objects have metaphysically basic conscious properties, collectively.

Note that this picture, the collectivity version of pluralized panpsychism, also solves one of the main problems for panpsychism, namely the so-called combination problem

\footnotetext{
18 See Chalmers (2013) for other versions of panpsychism, as well as another kind of argument for it. Note that the general morale below holds for many of these other versions as well; nothing in what follows hinge on Nagel's version in particular.

19 Though of course 'pan-' is a misnomer here in any case because few would claim that all objects whatsoever have conscious properties.
} 
(Chalmers 2013; Chalmers 2016). ${ }^{20}$ It seems fair to say that if each one of physical reality's (possibly more and more) basic objects instantiates consciousness, it is not exactly the same kind of consciousness we composite objects instantiate, but rather some simpler (or perhaps even another) kind of pre-consciousness (cf. Chalmers 2013). But then the question immediately arises: why do some combinations rather than others of these pre-conscious objects give rise to our kind of consciousness? The answer cannot be that it is metaphysically basic because that amounts to accepting emergent conscious properties, which is impossible by the argument's own lights.

If we go for the collective version of pluralized panpsychism, over panpsychism, this combination problem never arises. No individual more basic object has pre-conscious properties, but rather some pluralities have our ordinary consciousness, collectively. So, there is no pre-consciousness to arrange in any way to obtain ordinary consciousness; there is just ordinary consciousness as we know it, which turns out to be a plural collective property.

One might of course wonder why some pluralities rather than others have more or less ordinary conscious properties, but first of all, this is not a combination problem, and second, there is very little point in so wondering. It's like wondering why some particles rather than others have negative charge. If it's metaphysically basic, there is nothing more to say, at least not metaphysically speaking. Explanation has to start somewhere, and basic objects having basic properties is a non-ad hoc, non-arbitrary place to start. That is, we must take seriously the idea that a plural collective property is metaphysically basic. (This point is further discussed below, in connection with pannormism.)

So, just like I claimed in the case of normativity in Sect. 1 that the third position based on collectivity is much more plausible than the second position based on strong distributivity, so I claim here in the case of consciousness that the collectivity version of pluralized panpsychism is much more plausible than (distributive) panpsychism. The above employment of standard plural logic seems to be a general lesson missed by proponents of panpsychism. ${ }^{21}$

Now, let's get back to pannormism. I will henceforth focus exclusively on the third position from Sect. 1 above, the one based on collectivity, unless noted otherwise. Let's call it collective pluralized pannormism (CPP).

One might object that CPP is a misnomer since it is not really pan, so to speak, in the sense of everything basic having normative properties. According to CPP, some but only some pluralities of basic objects have normative properties, not every basic object, not to mention every basic plurality of objects. But, first of all, not even panpsychism

\footnotetext{
20 In fact, as far as I can tell, it solves all the different varieties of it, discussed in Chalmers (2016). It is perhaps the closest to what Chalmers (2016: 5.3) calls quantum holism, but note that it is importantly different, and so in a way that avoids the problems of quantum holism mentioned by Chalmers. It also arguably solves the problem of mental causation in pretty much the same way panpsychism is supposed to, so Chalmers' main motivation for panpsychism seems preserved as well. See Bohn (2016).

21 For further discussion on this point concerning panpsychism, see Bohn (2016). Though I have focused on Nagelian panpsychism in particular, I believe the general points also hold with respect to other versions of panpsychism (cf. Chalmers 2013); though due to limitations of space, I must leave this to the reader to judge for now. It is worth noting that Sellars (1971) too touches on many interesting points related to the present arguments, but unfortunately completely misses the idea of a plural collective property.
} 
is pan in that sense. For example, panpsychism does not claim that abstract objects are conscious, even if they are basic, only that each concrete basic object is. Second, and more importantly, what's in a name? If you think CPP is a misnomer, replace 'pannormism' with 'normism'. Nothing philosophically important hinges on this. I've simply called it pannormism because of its similarities to panpsychism. I believe a panpsychist should also be a pannormist, and embrace the pluralized collective version of her view.

One might also object that CPP ends up with the wrong kind of subject for the normative properties: normative properties are singular, not plural. For example, in the case of our toy example again, the epileptic seizure can be bad, but a plurality of neuron firings cannot be collectively bad, at least not in the same way. But this objection is confused. First of all, pluralities can be bad, witnessed by many mobs, or pluralities of gangsters. ${ }^{22}$ But second, more importantly, the argument is a matter of metaphysical grounding, not linguistic or conceptual analysis. If we want metaphysically basic normative properties in nature, but no emergent properties, it seems singular normative properties holding of non-basic objects are more fundamentally plural normative properties holding of basic objects collectively, as per the above argument.

One might also object that CPP ends up with the wrong kind of subject in another sense: normative properties hold, basically, of kinds (types), not their instances (tokens) (see Skarsaune 2015). But I for one reject the Platonic order of priority needed for such a position in favor of an Aristotelian order: a kind (type) has a normative property in virtue of instances (tokens) having that property, not the other way around.

One might also object that normativity is not special, compared to all or most other kinds of properties, so TDP would overgeneralize, i.e. the principle that $([\mathrm{Fx}] \&[\mathrm{Byy}] \mathrm{G}[\mathrm{Bx}]) \rightarrow[\mathrm{Fyy}]$ would by the same kind of argument hold for any or most properties F. But, or so the objection goes, the latter is obviously false, so it is false in the case of normativity (and perhaps consciousness) too. Either this kind of objection amounts to a simple denial of the premise that there is at least one instantiation of at least one metaphysically basic normative property F, i.e. they are all on a par, or it amounts to an affirmation that TDP holds for all metaphysically basic properties. But the former, the premise that there is at least one instantiation of at least one metaphysically basic normative property $\mathrm{F}$ is just that: a premise for the argument, and the latter, that TDP holds for all metaphysically basic properties is, by the above kind of argument, simply true. Most everyday properties (e.g. the property of being a rock) are not thus metaphysically basic, so TDP is logically irrelevant with respect to them, and most that are thus metaphysically basic (perhaps the property of being an electron) logically comply with TDP. What is special about normativity, and I'm tempted to say the same about consciousness, compared to other metaphysically basic properties (perhaps the property of being an electron), is that they are instantiated, at least seemingly, by non-basic objects. If these properties are metaphysically basic, I have argued that they must on pain of emergence therefore collectively trickle down the grounding chain of their instantiators as per TDP. That does not mean that normativity, or consciousness, is special compared to other metaphysically basic properties.

22 Parfit (1984) discusses another example where a group of people does something wrong even though each member of the group does nothing wrong. 
There is a triviality worry in the vicinity here. We should be able to say which properties do trickle down the grounding chain, and which don't. If either none or all do, then TDP becomes trivial. I have said that all metaphysically basic ones do on pain of emergence, but leave it open whether other metaphysically non-basic properties do as well; it doesn't really matter for my argument. For a toy example, consider a fusion of basic objects arranged chair-wise, e.g. the one I'm sitting in right now. Presumably, that fusion is grounded in the basic objects arranged chair-wise. The fusion also has the property of being a chair. Presumably it is not a metaphysically basic property: it has a full metaphysical explanation in other terms. Does the property of being a chair trickle down the grounding chain just like metaphysically basic normative properties do? In one sense it does, in another sense it doesn't. It does in the sense of it not being obviously false to say that the basic objects arranged chair-wise are collectively a chair. But it doesn't in the sense that being a chair can presumably be fully metaphysically explained in other terms, e.g. by the arrangement of the basic objects, how they physically hold together, our functional interest in sitting on them, etc. Metaphysically basic normative properties on the other hand has no such full metaphysical explanation in other terms, and must thus trickle down on pain of either not being real or being emergent. That distinction makes TDP non-trivial.

One might also object that CPP is objectionably brute in the sense that which pluralities of basic objects instantiate a basic plural collective normative property and which don't is a brute fact, and, one might add, this bruteness is at least as objectionable as the bruteness in emergent normative properties. But that is just not true. Yes, which pluralities of basic objects instantiate a basic plural collective normative property and which don't is a brute fact according to CPP, but no (stamping my foot, banging the table!), this bruteness is not as objectionable as the bruteness in emergent normative properties. What's objectionably brute in the case of emergence is that a basic property is instantiated by a non-basic object (without a full explanation), which is just not the case according to CPP. According to CPP, a basic property is instantiated by some basic objects, and so in a way that is no more objectionably brute than any other case of basic objects instantiating basic properties. Basic objects instantiating basic properties never, not even in principle, have a full explanation; that is what it is for them to be basic.

There is an arbitrariness worry in the vicinity here. According to CPP, it seems arbitrary which pluralities instantiate the basic normative properties and which don't. But note that this arbitrariness worry is the same for all metaphysically basic properties. Assume being located in region $r$ is a metaphysically basic property of a basic object. Well, it seems arbitrary why the object is located where it is as opposed to somewhere else. Assume having mass $\mathrm{m}$ is a metaphysically basic property of a basic object. Well, it seems arbitrary why the object has the mass it does as opposed to, say, twice that mass. More generally, all the so-called physical fine-tuning seems arbitrary (cf. Lewis and Barnes 2016). More controversially, what is identical to what seems arbitrary. Why is Batman identical to Bruce Wayne rather than Dick Grayson? In a sense, all the above cases, and many more, are arbitrary, but they are not objectionably arbitrary because they are brute facts of reality at the fundamental level. They are where reality starts out, by definition having no full metaphysical explanation. 
Maybe the worry is that it seems arbitrary that the plurality has the normative property without any one of its members having it? Because, if so, comparing the arbitrariness worry to singular cases as above might be misplaced. I'm not sure what to say other than that I just don't see why the plurality is a special worry here. We must take seriously the idea that there can be metaphysically basic plural collective properties, just like there can be metaphysically basic singular properties. So why is the plurality as such, which is just its members, supposed to create a special problem here?

Emergence on the other hand is objectionably arbitrary. Theoretically speaking, basic properties should first and foremost be instantiated by basic objects; they should not first and foremost be instantiated by non-basic objects. An emergent property is a basic property first and foremost instantiated by a non-basic object, so theoretically speaking it should not be instantiated where it is. We should therefore ask: Why is it thus instantiated by this non-basic object as opposed to that non-basic object, or by a basic object? It is not where reality starts out. It is objectionably arbitrary!

There is also a pushing-the-bump-around-under-the-rug worry in the vicinity here. Doesn't CPP just move the problem from lacking a full explanation of an emergent normative property to lacking a full explanation of why some pluralities instantiate the basic plural collective normative property and others don't? But the answer is no for the reasons given above as to why CPP is not objectionably brute and arbitrary, but emergence is.

One might also object that all plural collective properties must be emergent properties in the sense that they too must brutely instantiate when some things are put together in a certain way. But this objection is confused. By standard plural logic, a plurality of objects is nothing but those objects. So, for example, if I eat some cheerios, I eat those cheerios, not some composite (plural) object derived from or based on them (Boolos 1986). So, a plural collective property of some basic objects is a property of those basic objects, not of some non-basic object, and hence by definition of emergence not emergent. ${ }^{23}$

There is perhaps another triviality worry in the vicinity at this point. If the being of the non-basic object is nothing but what grounds it, and a plurality is nothing but its members, then of course the metaphysically basic properties (if not all properties) trickle down; how could they fail to do so? The standard understanding of the nonbasic object being nothing but what grounds it is not that it is identical with its ground, but that its nature, or what it is, is constitutively and fully metaphysically explained in terms of its ground. So one of its properties could fail to trickle down simply by it, the non-basic object, not having such a constitutive and full explanation in terms of its ground, i.e. by having an emergent property. So, the reason to believe that all metaphysically basic property, if not all properties, must trickle down is by virtue of denying the possibility of emergence. Now, as seen earlier, I believe that emergence is indeed impossible, but if you don't, you should not think that all metaphysically

\footnotetext{
23 It should go without saying (but I say it anyway) that a metaphysically basic plural collective property is not an emergent property in virtue of simply being collective. Collectivity and emergence are orthogonal matters. See below. This lesson is sorely missed in e.g. Sellars (1971).
} 
basic properties must trickle down the grounding chain. The conclusion that they do is non-trivial. ${ }^{24}$

One might also object that plural collective properties cannot be metaphysically basic, but must rather be derived from basic properties of, and relations among, each members of the plurality. For example, consider the case of the bad band without any individual member of the band being bad. Presumably, the band is bad because of some relation among the individual members, so the badness of the band is not a basic property. But this is just where such analogies break down. We must take seriously the idea that there can be metaphysically basic plural collective properties. Arguably, the objection is based on an unjustified metaphysical prejudice. First, rhetorically, why cannot plural collective properties be basic? There are no good reasons to think they cannot. Second, there might even be actual good reasons to the contrary. Quantum entanglement might be treated as a property of some particles that is not in any way a logical result of the singular properties of those particles (cf. Maudlin 1998; Bohn 2012). So, if quantum entanglement is a physically basic property, then we might have an actual case of a physically basic plural collective property. There is no reason to think that there cannot similarly be metaphysically basic plural collective properties. After all, as we have seen, they do substantial metaphysical work for us (see also Bohn 2012, 2016).

Some will no doubt object that emergent properties are simply more plausible than $\mathrm{CPP}$, and as such treat the above argument for CPP as a reductio in favor of emergent normative (and conscious?) properties. I can here only note that one person's modus ponens is another person's modus tollens on this point. As argued above, I find $\mathrm{CPP}$ to be theoretically much more satisfactory. According to CPP, metaphysically basic properties are instantiated where they should be (theoretically speaking): by metaphysically basic objects. I for one just cannot rest content with metaphysically basic properties being instantiated by metaphysically non-basic objects. It is objectionably brute and arbitrary. It is no natural resting point for thought. It cries out for an explanation. For theoretical purposes, I would rather reject all talk of normativity (or consciousness) being metaphysically basic, or all talk of one thing being grounded in others, than accept brute and objectionably arbitrary metaphysical emergence.

Some might also simply object by the incredulous stare. The incredulous stare is no argument, so it's hard to reply by arguments, but let it suffice to say that if some composite object a has a metaphysically basic normative property $\mathrm{F}$, and the being of $\mathrm{a}$ is grounded in the being of $\mathrm{bb}$, then I for one finds it more incredible to claim that $\mathrm{F}$ holds of a, but not of $\mathrm{bb}$, than to claim that $\mathrm{F}$ also holds of bb. First, the former entails emergence. Second, there is nothing more to the being of a than there is to the being of $b b$.

Another potential objection comes from the widely accepted thesis of normative (global) supervenience, the claim that no two (metaphysically) possible worlds are descriptively (non-normatively) indiscernible but normatively discernible. If CPP is true, such normative supervenience seems false. Assume CPP is true. It then seems

24 That being said, I believe composition is identity (cf. Bohn 2011, 2014a, b, 2016), so to the extent that parts ground wholes, I believe TDP trivially follows from Leibniz's Law. But the above argument for pannormism does not rest on the controversial thesis of composition as identity. 
metaphysically possible that all pluralities of basic objects simply fail to instantiate the metaphysically basic plural collective normative properties, on pain of inexplicable metaphysically necessary connections between some pluralities of basic objects and some basic normative properties. (Such necessary connections among basic things are perhaps even more objectionable than among non-basic things.) In short, given CPP, a descriptive zombie-world should be metaphysically possible. But then normative supervenience is false. Now, normative supervenience is of course a big metaethical issue we cannot adequately discuss here, and is also somewhat orthogonal to our present issue. But, in any case, let me just make a brief remark on this. Given normative realism as per our first initial assumption, metaphysical (normative) supervenience faces objectionable metaphysically necessary connections (see McPherson 2012), so if one holds on to the initial assumption, such supervenience should be rejected. Now, some might see this as a blow to the initial assumption, but I am not convinced. By distinguishing between normative necessity and metaphysical necessity as per Fine (2002) and Rosen 2014, we get a failure of metaphysical (normative) supervenience, but no failure of normative (normative) supervenience. That considerably softens the blow, in my mind. In fact, by weighing it up against each other, i.e. the package of normative realism and normative (normative) supervenience but no metaphysical (normative) supervenience on the one hand, and either no normative realism or normative realism and metaphysical (normative) supervenience but inexplicable metaphysically necessary connections on the other hand, I favor the former hand, both intuitively and theoretically, as well as metaphysically. But, again, this issue is somewhat orthogonal to present concerns, not a special problem for CPP in particular. ${ }^{25,26}$

Let me end on a related digression. Rosen (2014: fn.29) says about indefinite descending grounding chains in ethics, that to "my knowledge, no one has ever seriously suggested that ethics might have this structure, but it would be good to know whether this is a genuine (metaphysical) possibility." Arguably, I have just given one such (metaphysical) possibility, in the case of grounding being non-well-founded, indefinitely descending. But there are others as well, which we can easily see by the following principle, which I'll call the factual trickle-down principle:

$$
(\text { FTDP) : (Np\&qqGp) } \rightarrow \text { Nqq }
$$

where 'p' and 'qq' are factual variables, ${ }^{27}$ ranging over singular facts and pluralities of (one or more) facts, respectively, 'Np' means that $\mathrm{p}$ is normative, 'qqGp' means

\footnotetext{
25 Alternatively, one might try to argue that it is essential, or part of what it is to be some pluralities that they have certain metaphysically basic normative properties (cf. Fine 1994). But that is a bit too metaphysically hard-core for my taste.

26 On a different note: it is an interesting question whether CPP can be reconciled with priority monism (cf. Schaffer 2010), divine foundationalism (i.e. that God is the fundamental ground for all things), or any other position according to which there is only one object as the fundamental ground of all things. The worry is that in such a case the fundamental ground will have incompatible normative properties. I don't think this is an obstacle for CPP, but must leave the discussion of it for another time. Note also that priority monism and divine foundationalism (and other views according to which the fundamental ground is one and only one thing) violates the extensionality of grounding assumed in this paper. Thanks to a referee for this journal for pressing me on this point.

27 I treat 'true proposition' and 'fact' interchangably.
} 
that facts qq ground the fact $\mathrm{p}$, and 'Nqq' means that the plurality of (one or more) facts qq are normative.

As it stands, FTDP is ambiguous in several respects; its disambiguation leads to several different positions, but all of which entails indefinite descending grounding chains with respect to normativity, and hence in ethics too, if $\mathrm{G}$ is indefinitely descending. For example, 'Np' might mean one of two different things. On the one hand, it might mean that $\mathrm{p}$ has the (second-level) property of being normative in the sense of just being one of the normative facts. ${ }^{28}$ On the other hand, it might mean, focusing on atomic facts, that $\mathrm{p}=\mathrm{Fa}$, for some (first-level) normative property $\mathrm{F}^{29}$ The second way entails the first way, but the first way does not entail the second way. In both cases one must distinguish between $\mathrm{N}$ being weakly distributive, strongly distributive, and collective, in the same way we saw earlier. All in all, FTDP thus leads to at least six different positions to consider. I cannot consider any one of them here, but merely note that in all six cases, by virtue of $\mathrm{G}$ imposing a strict partial order on its facts, and in particular by its transitivity, FTDP logically entails scenarios of indefinitely descending chains of grounding, if $\mathrm{G}$ is indefinitely descending, just like Rosen (2014) wondered about. I see no good reason to think any one of them is (metaphysically) impossible (see Bohn 2017). ${ }^{30}$

Open Access This article is distributed under the terms of the Creative Commons Attribution 4.0 International License (http://creativecommons.org/licenses/by/4.0/), which permits unrestricted use, distribution, and reproduction in any medium, provided you give appropriate credit to the original author(s) and the source, provide a link to the Creative Commons license, and indicate if changes were made.

\section{References}

Barnes, E. (2012). Emergence and fundamentality. Mind, 121(484), 873-901.

Bedau, M. A., \& Humphrey, P. (Eds.). (2008). Emergence: Contemporary readings in philosophy and science. Cambridge: MIT Press.

Bliss, R. (2013). Viciousness and the structure of reality. Philosophical Studies, 166, 399-418.

Bliss, R., \& Trogdon, K. (2014). Metaphysical grounding. In E. N. Zalta (Ed.), The stanford encyclopedia of philosophy (Winter 2016 ed.). https://plato.stanford.edu/archives/win2016/entries/grounding/.

Boden, M. A. (Ed.). (1996). The Philosophy of artificial life. Oxford: Oxford University Press.

Bohn, E. D. (2011). Commentary on 'parts of classes'. Humana Mente, 19, 151-158.

Bohn, E. D. (2012). Monism, emergence, and plural logic. Erkenntnis, 76(2), 211-223.

Bohn, E. D. (2014a). From Hume's dictum via submergence to composition as identity or mereological nihilism. Pacific Philosophical Quarterly, 95(3), 336-355.

Bohn, E. D. (2014b). Unrestricted composition as identity. In D. Baxter \& A. Cotnoir (Eds.), Composition as identity. Oxford: Oxford University Press.

\footnotetext{
28 The same goes for qq: they have the (second-level) property of being normative in the sense of being among the normative facts.

29 The same goes for qq: at least one of them/each one of them/ all of them is/are of the form Fa, for some (first-level) normative property F. See below.

30 Thanks to Ricki Bliss, Ben Caplan, David Chalmers, Jeff Dunn, Matti Eklund, Torfinn Huvenes, AnnaSofia Maurin, Tristram McPherson, Debbie Roberts, Knut Olav Skarsaune, Kelly Trogdon, Pekka Vayrynen, two anonymous referees, and audiences at DePauw University, Uppsala University, and the University of Oslo.
} 
Bohn, E. D. (2016). Composition as Identity and plural Cantor's theorem. Logic and Logical Philosophy, 25(3), 411-428.

Bohn, E. D. (December, 2016.). Panpsychism, the combination problem, and plural logic.

Bohn, E. D. (2017). Indefinitely descending ground. In R. Bliss \& G. Priest (Eds.), Reality and its structure. Oxford: Oxford University Press. 2017.

Boolos, G. (1986). To be is to be a value of a variable (or some values of some variables). Journal of Philosophy, 81(8), 430-449.

Chalmers, D. (2013). Panpsychism and panprotopsychism. In T. Alter \& Y. Nagasawa (Eds.), Consciousness in the physical world. Oxford: Oxford University Press. 2015.

Chalmers, D. (2016). The Combination Problem for Panpsychism. In L. Jaskolla \& G. Bruntrup (Eds.), Panpsychism. Oxford : Oxford University Press.

Coleman, S. (2013). The real combination problem: Panpsychism, micro-subjects, and emergence. Erkenntnis, 79, 19-44.

Dixon, T. S. (2016). What is the well-foundedness of grounding? Mind, 125(498), 439-468.

Enoch, D. (2007). An Outline of an argument for robust metanormative realism. In K. Bennett \& D. Zimmerman (Eds.), Oxford studies in metaethics (Vol. 2). Oxford: Oxford University Press.

Fine, K. (1994). Essence and modality. Philosophical Perspectives, 8, 1-16.

Fine, K. (2001). The question of realism. Philosopher's Imprint, 1(1), 1-30.

Fine, K. (2002). Varieties of necessity. In T. S. Gendler \& J. Hawthorne (Eds.), Conceivability and possibility. Oxford University Press.

Fitzpatrick, W. (2008). Robust ethical realism, non-naturalism, and normativity. In K. Bennett \& D. Zimmerman (Eds.), Oxford studies in metaethics (Vol. 3). Oxford: Oxford University Press.

Lewis, G. F., \& Barnes, L. A. (2016). A fortunate universe: Life in a finely tuned cosmos. Oxford: Oxford University Press.

Maudlin, T. (1998). Part and whole in quantum mechanics. In Elena Castellani (Ed.), Interpreting bodies. Princeton: Princeton University Press. 1998.

McDaniel, K. (2007). Brutal Simples. In K. Bennett \& D. Zimmerman (Eds.), Oxford studies in metaphysics (Vol. 3). Oxford : Oxford University Press.

McDaniel, K. (2008). Against composition as identity. Analysis, 68(2), 128-133.

McPherson, T. (2012). Ethical non-naturalism and the metaphysics of supervenience. In K. Bennett \& D. Zimmerman (Eds.), Oxford studies in metaethics (Vol. 7). Oxford: Oxford University Press.

Nagel, T. (1979). Panpsychism. In T. Nagel (Ed.), Mortal questions. Oxford: Oxford University Press. 1979.

O’Connor, T., \& Wong, H. Y. (2015). Emergent properties. In E. N. Zalta (Ed.), The stanford encyclopedia of philosophy (Summer $2015 \mathrm{ed).} \mathrm{https://plato.stanford.edu/archives/sum2015/entries/}$ properties-emergent/.

Oliver, T., \& Smiley, A. (2013). Plural logic. Oxford: Oxford University Press.

Parfit, D. (1984). Reasons and persons. Oxford: Oxford University Press.

Parfit, D. (2011). On what matters (Vol. 1-2). Oxford: Oxford University Press.

Rabin, G. O., \& Rabern, B. (2016). Well founding grounding grounding. Journal of Philosophical Logic, 45(4), 349-379.

Raven, M. (2015). Ground. Philosophy Compass, 10(15), 322-333.

Rosen, G. (2010). Metaphysical dependence: Grounding vs. reduction. In B. Hale \& A. Hoffman (Eds.), Modality. Oxford: Oxford University Press.

Rosen, G. (November, 2014.). Normative necessity.

Rosen, G. (2015a). Real definition. Analytical Philosophy, 56(3), 189-209.

Rosen, G. (June, 2015b.). Defining an object.

Sellars, W. (1971). Science, sense impressions, and sensa: A reply to Cornman. Review of Metaphysics, 24(3), 391-447.

Schaffer, J. (2009). On what grounds what. In D. Chalmers (Ed.), Metametaphysics (p. 2009). Oxford: Oxford University Press.

Schaffer, J. (2010). Monism: The priority of the whole. Philosophical Review, 119(1), 31-76.

Shafer-Landau, R. (2003). Moral realism. Oxford: Oxford University Press.

Skarsaune, K.O. (2015). How to be a moral platonist. In K. Bennett \& D. Zimmerman (Eds.), Oxford studies in metaethics (Vol. 10). Oxford: Oxford University Press.

Strawson, G. (2006). Realistic monism: Why physicalism entails panpsychism. Journal of Consciousness Studies, 13(10-11), 3-31.

Susskin, L., \& Friedman, A. (2015). Quantum mechanics. London: Penguin. 
Tononi, G. (2008). Consciousness as integrated information: A provisional manifesto. Biological Bulletin, $215,216-242$.

Wilson, J. (2014). No work for a theory of grounding. Inquiry, 57(5-6), 535-579.

Wilson, J. (2015). Metaphysical emergence: Strong and weak. In T. Bigaj \& C. Wuthrich (Eds.), Metaphysics in contemporary physics. Leiden: Brill Rodopi. 2015.

Yi, Beyong-Uk. (2005). The logic and meaning of plurals. Part I. Journal of Philosophical Logic, 34, 459-506.

Yi, Beyong-Uk. (2006). The logic and meaning of plurals. Part II. Journal of Philosophical Logic, 35, 239-288. 